\title{
PRODUÇÃO DE BRIQUETES COM RECURSO AOS RESÍDUOS RESULTANTES DA PRODUÇÃO FLORESTAL (FINOS DE CARVÃO E PAPEL)
}

\author{
Manuel Pastor Francisco Conjo ${ }^{1}$
}

RESUMO: O carvão vegetal é um material altamente friável quando submetido ao impacto, parte se transforma em finos, fato considerado um problema para a maioria dos sistemas produtivos. Por outro lado, encontramos o papel descartado em várias atividades, figurando-se também como um grande problema ambiental. Assim, este estudo teve como objetivo produzir briquetes utilizando finos de carvão vegetal agregados ao papel para fins energéticos utilizando uma metodologia simples, acessível ao uso pelas comunidades mais carenciadas. Os finos de carvão e papel foram agregados de forma manual, com recurso a materiais simples de fácil acesso, água para ensopar o papel transformando-o em massa, uma tabua e taco pata triturar os finos, luvas de látex e lona sintética para secagem. Constatou-se que os finos de carvão vegetal agregados a massa de papel num processo de compactação manual, apresentam uma boa eficiência para o uso doméstico e outros, uma vez que detém poder calorifico e a sua combustão é estável. Esses resultados demostraram que os finos de carvão vegetal e papel possuem potencial para produção de briquetes e posterior utilização energética.

Palavras-chave: Reaproveitamentos de resíduos, conservação ambiental, briquetagem, combustível, papel descartado.

ABSTRACT: Charcoal is a highly friable material when subjected to impact, part of which becomes fines, a fact considered a problem for most production systems. On the other hand, we find paper discarded in various activities, also representing a major environmental problem. Thus, this study aimed to produce briquettes using charcoal fines added to paper for energy purposes using a simple methodology, accessible for use by the most deprived communities. The charcoal and paper fines were added manually, using simple materials with easy access, water to soak the paper into mass, a board and taco to grind the fines, latex gloves and synthetic canvas for drying. It was found that the charcoal fines added to the paper mass in a manual

${ }^{\text {I }}$ Bacharel e Licenciado em Ensino de Geografia pela Universidade Pedagógica de Maputo - Moçambique. Técnico Superior em Higiene e Segurança no Trabalho e Meio Ambiente pela Ensine Moçambique. Mestrado em Gestão Ambiental pela Universidade Pedagógica de Maputo - Moçambique. Doutorando em Ciência Florestal pela Universidade Federal de Viçosa - Minas Gerais - Brasil. Instituição: Universidade Pedagógica de Maputo/Universidade Federal de Viçosa. E-mail: pastorconjooo7@gmail.com /m.conjo@hotmail.com 
compaction process, present a good efficiency for domestic and other uses, since it has calorific power and its combustion is stable. These results demonstrated that the charcoal and paper fines have the potential for the production of briquettes and subsequent energy use.

Keywords: Waste reuse, environmental conservation, briquetting, alternative fuel, discarded paper.

\section{INTRODUÇÃO}

Uma das formas de preservação do meio ambiente, é a conservação da natureza, quer seja pela proibição de extração de alguns recursos, extração racional e ou mesmo a redução no volume de extração, diminuindo a pressão que se exerce sobre os recursos naturais, o que por outro lado, reduz o volume de resíduos gerados para o meio ambiente. Sendo que uma das formas de reverter esse ciclo, é buscar um mecanismo de dar destino coreto aos resíduos gerados nos diferentes processos, dando enfoque para esta abordagem, o aproveitamento dos resíduos resultantes da produção de florestal.

O carvão vegetal, também conhecido como carvão de biomassa, é produzido a partir da madeira pelos processos de carbonização ou pirólise (FAO, 20I6; KIRUKI et al., 20I9) e representa uma forma de energia renovável de expressiva importância no mundo, sendo uma das fontes mais utilizadas principalmente nos paises em vias de desenvolvimento, especialmente no brasil, uma vez que o país é o maior produtor mundial desse insumo, com aproximadamente um quarto da produção mundial, seguido de países como Etiópia, Nigéria e Índia ( Bailis et al., 2013; Machado et al, 2010).

Ao contrário do que aconteceu nos países desenvolvidos, o uso industrial do carvão vegetal ainda é largamente praticado, sendo quase a totalidade da produção brasileira destinada ao setor siderúrgico para a produção de ferro-gusa, aço e ferro-ligas. $O$ setor residencial consome cerca de $9 \%$, seguido pelo setor comercial com I,5\%, sendo representado por pizzarias, padarias e churrascarias (Machado et al., 2010; Bailis et al., 2013).

O problema associado à característica física do carvão vegetal é a sua friabilidade, ou seja, sua capacidade de se fragmentar em pequenos pedaços e a geração de finos que acompanham as cinzas no âmbito de sua utilização, quer a nível industrial ou domestico (Delatorre et al, 2020). Durante a produção, o transporte e o manuseio do carvão produzem em 
torno de $25 \%$ de finos, o que dificulta ou, até mesmo, inviabiliza a sua utilização (Rousset et al., 20II). Nesse contexto, fica clara a necessidade da recuperação e reutilização desses finos, uma vez que eles possuem grande potencial energético. A briquetagem, por exemplo, permite a reutilização dos finos na forma de biocombustível sólido para a geração de energia, transformando-os em um produto com valor agregado. Onde, para este trabalho ira-se aglutinar os finos de carvão ao papel residual, garantindo o reaproveitamento de dois potenciais resíduos resultantes da produção florestal.

O processo de briquetagem consiste na aplicação de pressão a uma massa de partículas, com ou sem a adição de ligante e temperatura. A briquetagem do carvão vegetal na forma de finos e massa de papel se faz a partir da sua compactação com o auxílio de um aglutinante, a fim de proporcionar a coesão nos briquetes. Em princípio, qualquer material pode ser utilizado como um aglutinante, e a escolha do material ligante deve ser realizada de modo que ele não prejudique as características energéticas dos briquetes (diminuindo o seu poder calorífico ou aumentando seu teor de voláteis e cinzas) e não gere gastos que inviabilizem economicamente a produção dos briquetes (Magalhães; da Silva; de Castro, 2018). Neste caso, não sera necessario um aglutinante especifico pois o papel, na sua composicao já contem essa propriedade, a lignina que possui um poder de colagem.

Nesse contexto, este trabalho teve como objetivo produzir briquetes de finos de carvão vegetal desperdiçados e papel residual resultante do descarte em várias em atividades, onde minimiza-se o problema de excesso de resíduos na natureza e dá-se uma nova utilidade, acreditando-se que, usando-se uma matéria prima residual, aparentemente sem utilidade, pode ser uma alternativa viável de combustível para as comunidades desfavorecidas, tornando mais evidente este trabalho, por poder-se produzir um produto com certo valor comercial e de uso sem que haja extração de recurso, mas pelo contrário, garantindo a sustentabilidade do meio ambiente. Por essa razão, propõe-se uma metodologia bastante simples acessível a qualquer pessoa que tenha interesse, o que torna este estudo ainda mais interessante e diferenciado em que em seus processos de produção parte da matéria prima não necessariamente um produto residual e por empregar em suas metodologias elementos que apresentam algum custo financeiro, dificultando sua viabilidade a nível comunitário. Este é o motivo que leva com que 
nesta fase todo processo seja manual, mas com resultados viáveis, visto que, briquetes foram produzidos e testados, apresentando uma eficiência aceitável para o uso, principalmente doméstico.

\section{MATERIAL E MÉTODOS}

\section{I. Material Utilizado}

Como forma de garantir a sustentabilidade ambiental e materializar a política dos três R's - reduzir, reciclar e reutilizar, com vista a reduzir o excesso de resíduos no ambiente e dar uma nova utilidade a esses materiais, numa primeira fase, como se referiu na introdução, propõe-se a utilização de uma metodologia muito simples, que seja de alcance de qualquer interessado, sobre tudo nas comunidades com poucos recursos e técnicas, conforme pode-se perceber na figura I

Fig.I Imagem com materiais utilizados no processo de produção de briquetes

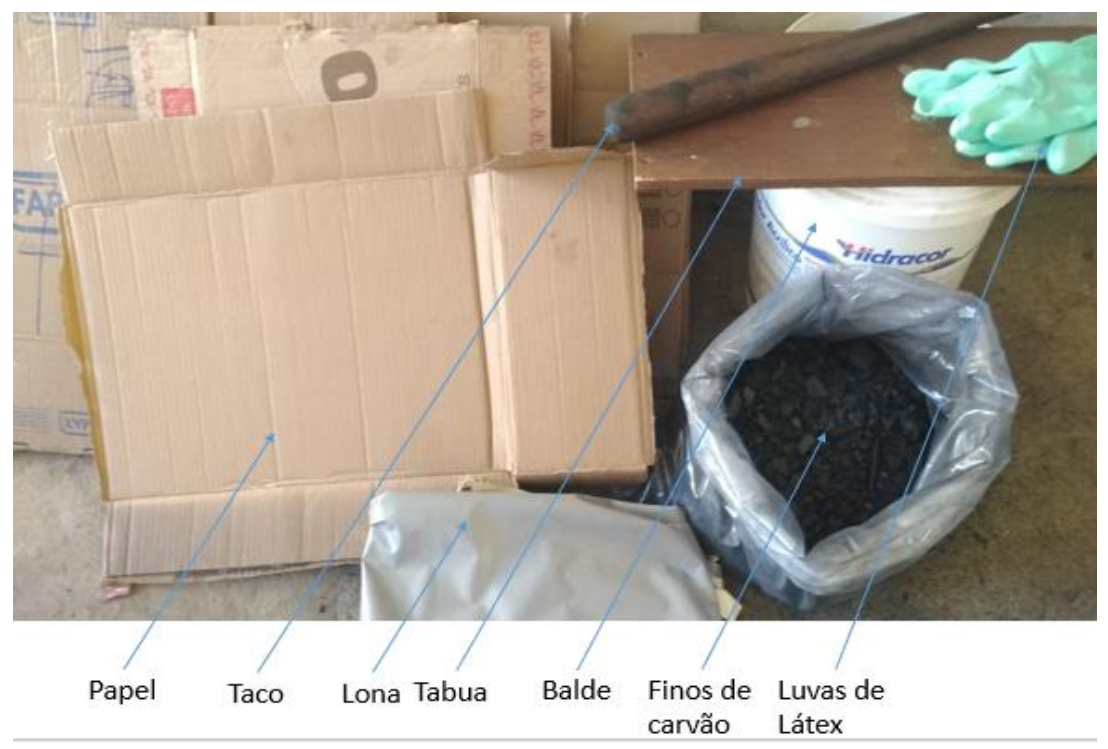

\section{I.I. Finos de carvão}


Os finos de carvão vegetal utilizados na confecção dos briquetes são provenientes das cinzas resultantes da utilização de lenha e carvão em diversos locai onde se manuseia este produto, uma vez que o carvão, pela suas caraterísticas físicas, desintegra-se com muita facilidade, como referiu-se anteriormente (Magalhães et al., 2019). Mais a diante, pode-se obter junto aos produtores de carvão e moinha de carvão.

Iremos triturar os finos coletados, para que possuam mesma granulometria, o que acreditamos que determina o poder calorifico, assim como densidade e consistência dos briquetes. Esses finos na maioria das vezes não têm uma aplicação concreta, daí que acabam sendo descartados como resíduos sólidos e recolhidos para lixão. Com esta produção pretendese a partir desses finos aglutinados ao papel, que por conter na sua composição a lignina, o que permite que haja colagem entre os finos e o papel amassado com água.

\subsubsection{Papel}

O papel para a produção dos briquetes foi recolhido nos diferentes pontos de deposição de resíduos em Viçosa, resultante do descarte de papel usado sem mais utilidade, aparentimente, nos diversos sectores. A demais, similarmente aos finos, a recolha da materia prima (papel descartado) poderá ocorrer a uma escala maior.

Refira-se que para este processo não há exclusão de papel, todo ele é útil das folhas do papel $\mathrm{A}_{4}$, jornais, revistas as cartulinas, desde que a ele não esteja adicionado o plastico.

\subsection{3. Água}

A água é elemento essencial no processo de produção de briquetes, uma vez que o papel que se aglutina ao carvão precisa antes, ser colocado de molho por 2 dias para que se dissolva e se transforme em massa depois de amassado e não só, a água ativa a lignina contida no papel, que imprescindível no processo de aglutinação aos finos. $O$ processo é todo realizado na presença de água até fase de secagem. Outro aspecto importante, é que a água usada pode ser 
resultante do processo de lavagem de louca e ou outros usos desde que não contenha elementos químicos para não comprometer a qualidade dos briquetes.

\subsubsection{Recipiente para amassar o papel}

Foi usado um baldes de 201 para a mistura do papel a água, até que fique totalmente mole para que seja amassado, tornando-se uma massa pastosa fácil de manipular.

\subsubsection{Luvas de látex}

As luvas serão utilizadas no processo de revolver e amassar o papel em banho maria, após dois dias de dissolução. As luvas são também utilizadas no processo de compactação manual, processo que em outra fase do projeto poderá ser substituído por uma maquina de briquetagem.

\subsubsection{Tabua e taco}

Uma tabua de madeira foi usada para esmagar os finos com maior granulometria de modo a tornar todos eles numa medida quase que uniforme. Como triturador utilizou-se uma tala de madeira.

\subsubsection{Lona sintética}

Para o processo de secagem, foi usada uma lona sintética, onde as bolinhas de briquetes produzidas são colocadas ao ar livre para um processo de secagem.

\subsection{Confecção dos Briquetes}

O processo de confecção de briquetes começa pela recolha e preparação dos materiais e equipamentos essenciais para a sua produção, finos de carvão, papel, balde, luvas, taboa, tala, lona sintética e água. Sendo em primeiro recolhido os finos junto aos locais acima mencionados e em seguida o papel nos diferentes pontos de deposição. Esse material é armazenado no local 
de confecção, quanto se prepara os objetos de preparo. Os briquetes foram produzidos em temperatura ambiente e processo de compressão manual de baixa pressão (Magalhães et al., 2019).

I. Fez-se teste de resíduos celulósicos - papel como material aglutinante dos briquetes. O papel é recortado em partes pequenas para redução do tamanho e facilitar o seu amolecimento. Em seguida é mergulhado no recipiente preparado para o processo de banho maria (balde de 201 ), por um período de 2 dias, até que fique totalmente ensopado na água para permitir que se amasse com facilidade. $O$ balde devera conter $80 \%$ de sua capacidade para ensopar cerca de $3 \mathrm{~kg}$ de papel, como pode ver na figura abaixo.

Fig. 2 Papel recortado e mergulhado na água para o processo ensopamento.

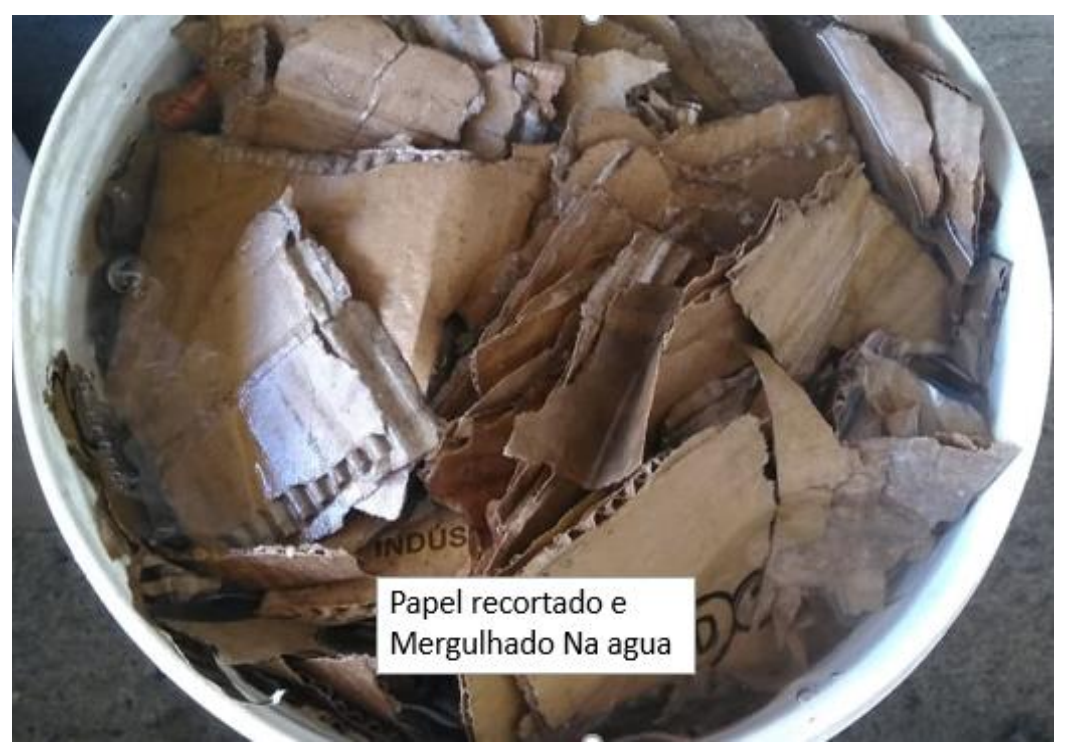

2. Paralelamente ao processo de amolecimento do papel na água, por dois dias, procede-se ao tratamento dos finos de carvão $(3 \mathrm{~kg})$, que são triturados com recurso a tabua e tala, de modo a deixá-los quase na mesma granulometria para uniformizar o poder calorifico em cada bolinha de briquete produzido, como ilustra a figura 3.

Fig. 3 Processo de trituração dos finos de carvão 


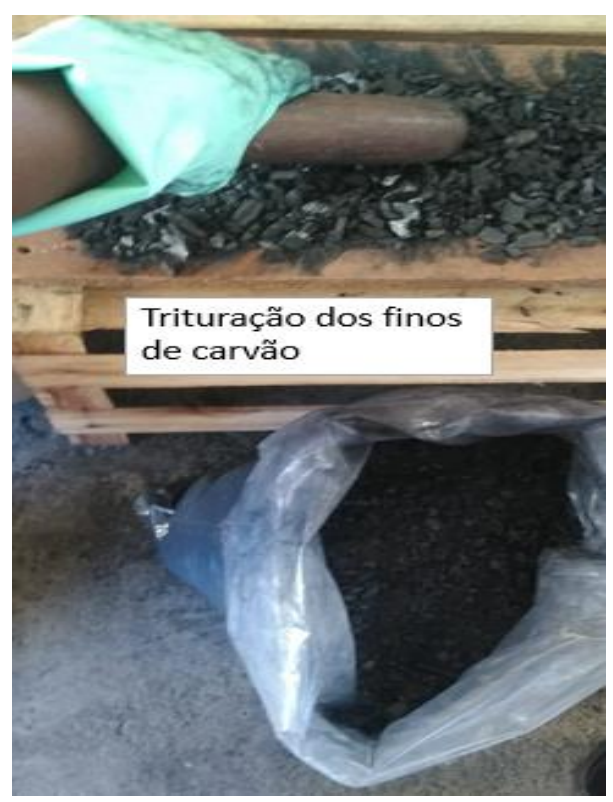

3. Findos dois dias, com uso de luvas de látex impermeáveis, procede-se ao revolvimento do papel mergulhado na água, onde exercendo uma certa força, amassa-se até que o papel ensopado se transforme em uma massa bem pastosa, misturada a água que, permite despoletar a evidencia do poder de colagem contido na composição do papel. Ver a Fig. 4 .

Fig. 4 Processo de amansamento do papel

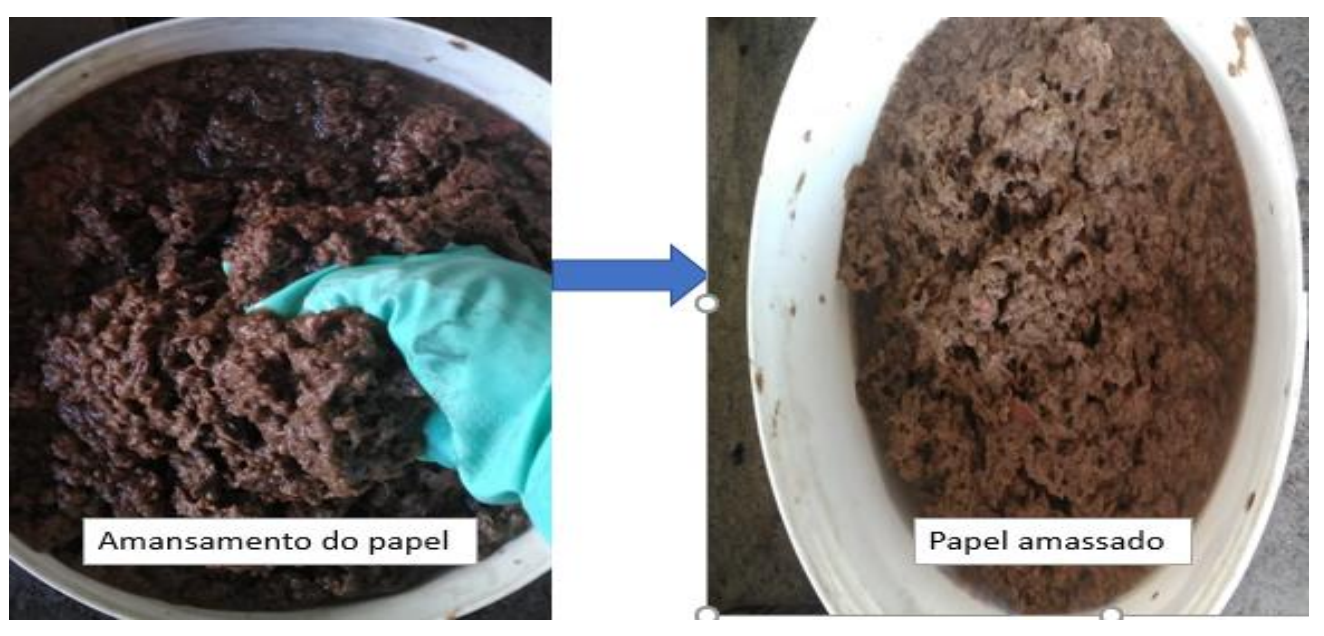

4. O papel transformado em massa de papel, é misturado aos finos de carvão já devidamente triturado e com granulometria quase que uniformizada. Procede-se então 
ao amassamento desses dois elementos, até se aperceber que estão totalmente misturados, o que se pode observar pela distribuição dos finos na massa de papel, observável na imagem abaixo.

Fig. 5 Processo de mistura da massa de papel aos finos de carvão

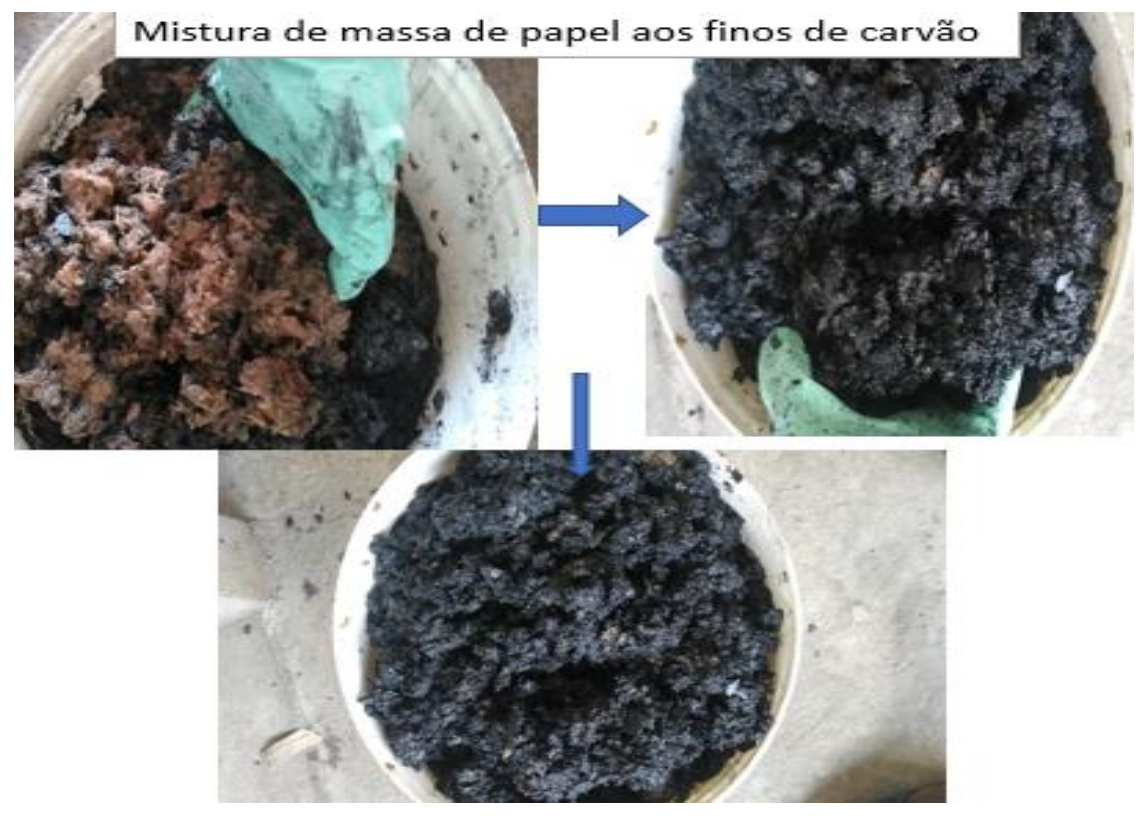

5. Inicia-se então a fase de compactação, onde coloca-se uma quantidade suficiente para manusear com a palma da mão e num processo de aperto, compacta-se a massa de papel misturada aos finos de carvão até que ganhe forma, de preferência redonda e fique consistente, conforme ilustrado na figura 6, abaixo.

Fig. 6 Processo de compactação da massa de papel e finos para produção de briquetes. 


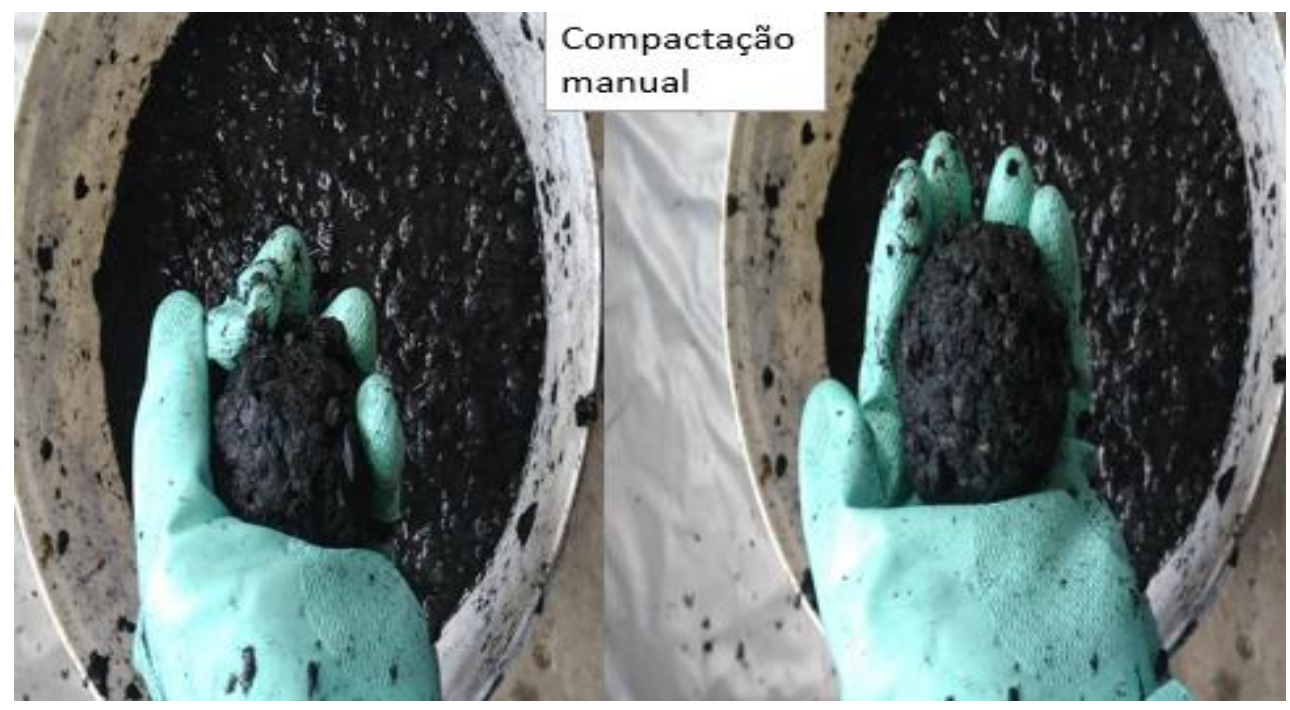

6. Para terminar, as bolinhas produzidas, são colocadas sobre a lona sintética, de preferência em um lugar bem arejado e na presença de raios solares, para o processo de secagem que dura em médias 2 a 5 dias dependendo da temperatura ambiente, ao fim dos quais os briquete podem ser recolhidos, embalado e prontos para o uso. Reiterando, que o uso das luvas é indispensável no decorrer de todo o processo, ilustrado na figura abaixo.

Fig. 7 Processo de secagem dos briquetes ao ar livre.

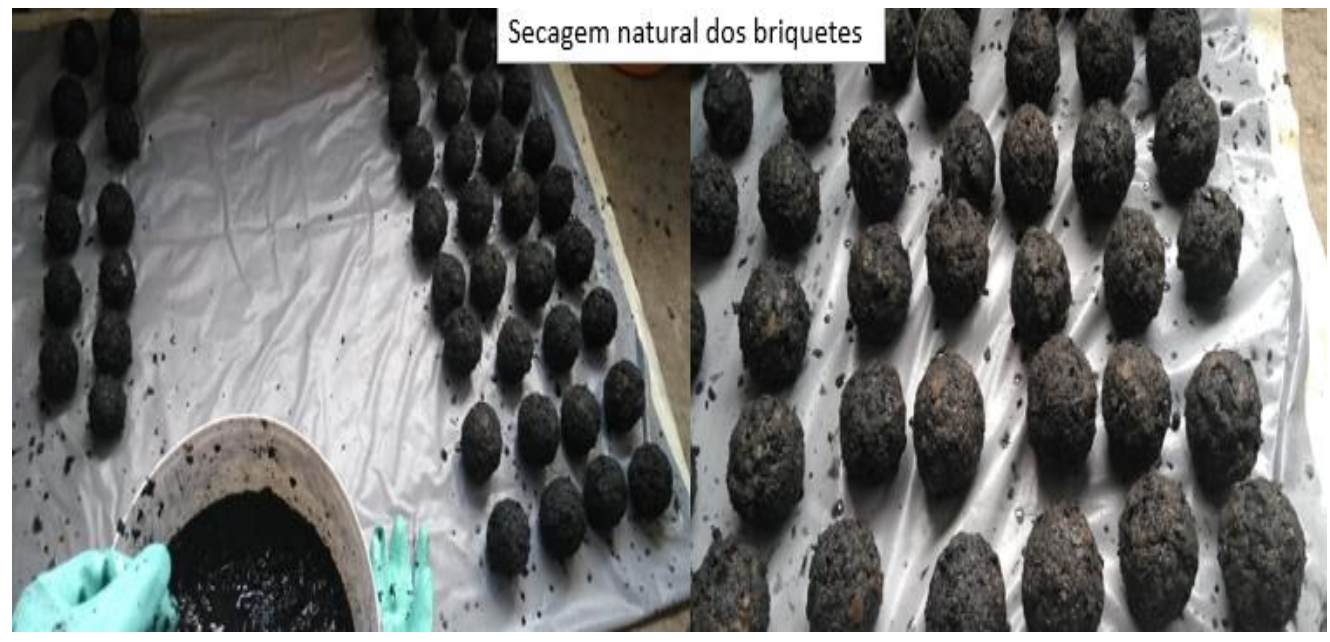


Todo o processo explicado, que é feito na ausência de qualquer equipamento de produção e com recurso a matéria prima genuinamente residual, resultante da produção florestal, pode-se representar pelo fluxograma a baixo, figura 8 .

Fig. 8 Fluxograma ilustrativo do processo de produção de briquetes

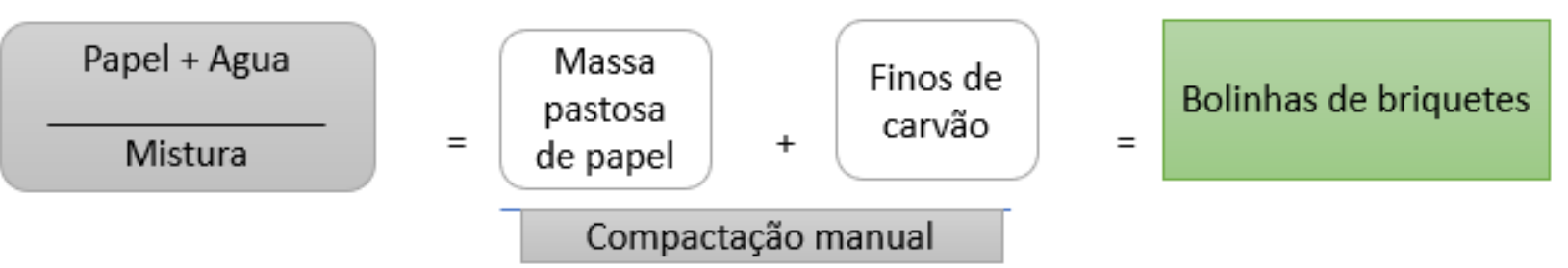

Tal como se referiu anteriormente, a demais, dependendo dos resultados obtidos, perspectivamos uma metodologia bastante melhorada de produção, com recurso a um amassador e um compactador eletromecaanico com moldes diferenciados e diferentes ingrenagens de compressão para definir a solidiz e a densidade do briquete para diferentes usos, onde a briquetagem (prensagem) do material homogeneizado será realizada no interior de um molde metálico cilíndrico ou cubico, utilizando-se uma prensa hidráulica com capacidade de compressao alternada.

\section{RESULTADOS}

RI: Para além de serem totalmente sustentáveis sob ponto de vista ambiental, por terem sido produzidos pela agregação de dois resíduos, por outro lado, os finos de carvão com poder calorifico, mas com fraca volatilidade, quando agregados ao papel, também combustível, com poder calorifico, mas com forte volatilidade, gera-se um equilíbrio, onde se tem um controlando o outro, o que resulta em um combustível misto com ambas caraterísticas, menos volátil, calorifico e estável sem fumaça, como pode notar com a figura abaixo.

Fig. 9 Teste de combustão dos briquetes produzidos 


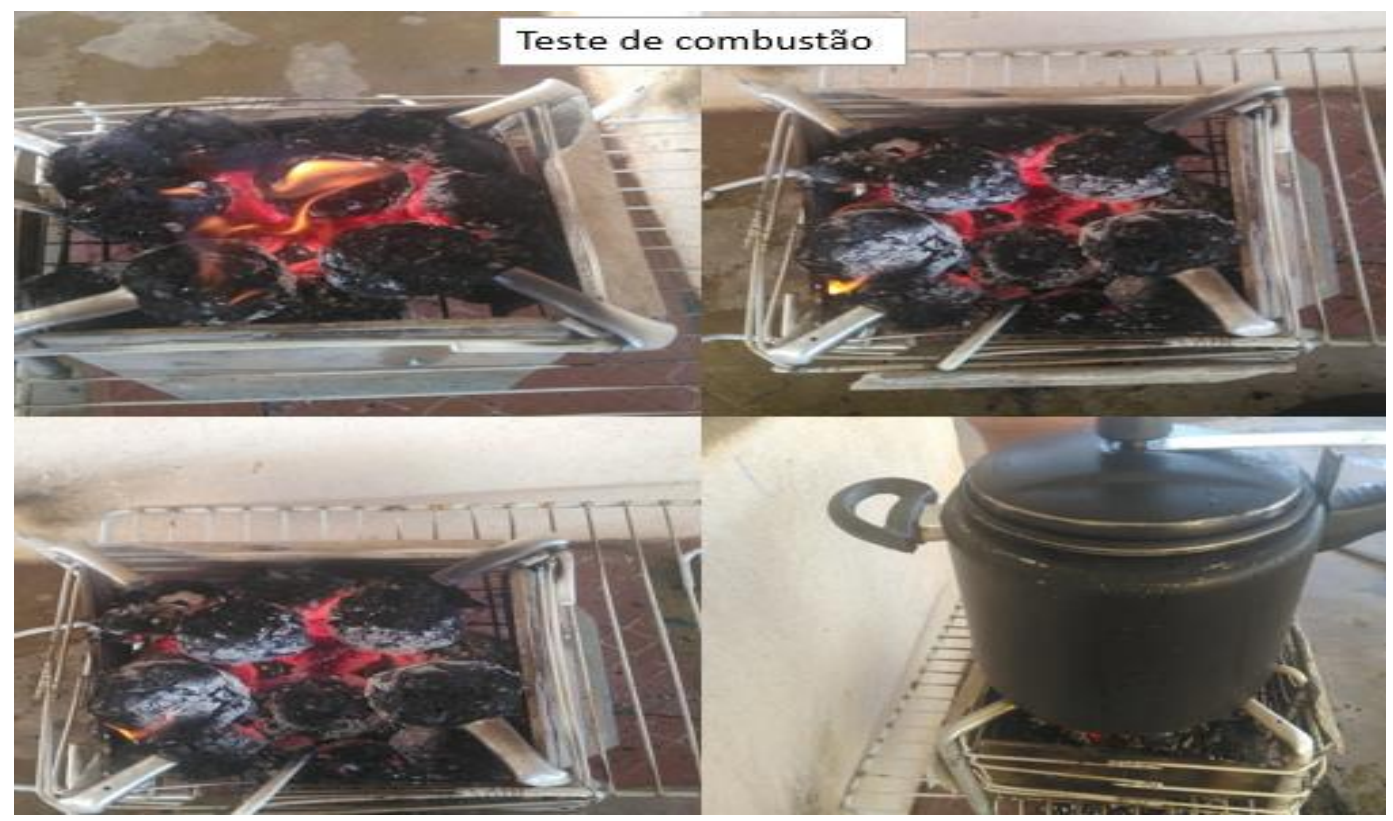

R2: Os finos de carvão aglutinados ao papel amassado, agregam um valor calorifico, tornando os briquetes resultantes um potencial combustível alternativo para o uso doméstico principalmente, mas também, dependendo do processo de sua confecção, volume e densidade, podem ser aplicados a outros usos, como por exemplo, churrascarias, pizzarias, pequenas panificadoras e outros fornos.

R3: Os briquetes produzido com recurso aos finos de carvão e papel, ambos produtos residuais o que os torna sobe ponto de vista de conservação ambiental viáveis, percebeu-se que reúnem eficácia para a confecção de alimentos, observável a partir da tabela abaixo, que se baseiam no ensaio realizado no ferver da água, onde faz-se a análise de algumas variáveis que se achou pertinentes.

Tab. I Analise de variáveis para avaliar a eficácia dos briquetes

\begin{tabular}{|l|c|}
\hline \multicolumn{1}{|c|}{ Variáveis e analise } & Briquetes \\
\hline $\begin{array}{l}\text { Tempo médio de combustão } \\
(\mathrm{min})\end{array}$ & 52 \\
\hline Tempo para água ferver $(\mathrm{min})$ & $\mathrm{I2}$ \\
\hline Quantidade $(\mathrm{kg})$ & 450 \\
\hline Chama & Estável \\
\hline Fumaça & Pouca \\
\hline
\end{tabular}




\begin{tabular}{|l|l|}
\hline Produção de cinzas & Normal \\
\hline Cheiro & Normal \\
\hline
\end{tabular}

R4: Os briquetes podem ter tamanho, peso, densidade e espessura variada consoante o modo de preparo e quantidade de massa de finos e papel utilizada.

\section{DISCUSSÕES}

Dr: De acordo com Dias Junior et al. (2016). A vantagem da briquetagem de resíduos de biomassa tem sido apontada ainda sob o ponto de vista ambiental e econômico, considerando a alta disponibilidade desses materiais.

A análise dos briquetes produzidos confirmou a existência de elevados teores de materiais voláteis nos briquetes. Todavia, considera-se percentuais entre $30 \%$ a $40 \%$ de materiais voláteis normais para diversas aplicações bioenergéticas, podendo ainda maiores valores ser encontrados, uma vez que a referida característica é fortemente influenciada pela matéria- -prima de origem, tipo de arvore que se utilizou na produção de carvão e o tipo de papel (Dias Junior et al, 2016). Os altos teores de matérias voláteis são desejados em situações que necessitem de formações de labaredas como lareiras, olarias, fornalhas e etc., sendo dessa forma, recomendados para os referidos usos. Dias Júnior et al. (2018), argumentam que, nos usos onde não seria recomendável a formação de chamas durante o aquecimento, como nas lareiras e forjas, os briquetes mais indicados são aqueles com os teores mais elevados de carbono fixo, neste caso, os briquetes com resíduos celulósicos e moinha de carvão vegetal na composição. Os poderes caloríficos superiores e inferiores apresentados pelos briquetes denotam que os mesmos apresentam potencial para diversas aplicações bioenergéticas.

D2: De forma geral, os resíduos provenientes da biomassa florestal apresentaram os maiores teores de carbono o que contribui para seu poder calorífico, possibilitando a geração de bioenergia a partir dos mesmos (Protásio et al, 2012).

A qualidade de energia produzida no processo de combustão normalmente é quantificada pelo poder calorífico de um combustível, tida como a quantidade de calor desprendido pela combustão completa de uma unidade de volume ou massa do combustível 
(Borges et al, 2008). De acordo com De Sena (2005), para um bom rendimento térmico na combustão, o combustível deve possuir uma elevada quantidade de carbono fixo e materiais voláteis, além de alto poder calorífico, condições que estão estabelecidas olhando para o parágrafo acima. Quanto maior o teor de carbono e hidrogênio, melhor será a eficiência combustão na liberação de energia, que justifica a eficiência dos briquetes de finos de carvão e papel.

Por demonstrar o melhor desempenho energético, evidencia-se que os finos de carvão vegetal apresentam características energéticas satisfatórias para o ramo energético, além de sua capacidade com fonte de bioenergia para uso em caldeiras, gaseificadores e como matéria-prima para produção de combustíveis sólidos adensados como briquetes e pellets, visto que, existem estudos da utilização desse material como "mix", em briquetes e pellets, aumentando de forma gradativa as propriedades químicas e físicas (Vieira et al., 2018).

Por sua vez, a lignina contida no papel, apresenta um conteúdo de carbono cerca de 50\% maior do que o encontrado nos polissacarídeos, portanto apresenta um potencial realmente grande para produção de energia. Além disso, os extrativos voláteis são importantes na queima direta da madeira, pois se degradam mais rapidamente e ajudam a manter a chama de combustão (De Oliveira et al., 2020)

D3: Baseado nos estudos realizados por Quirino (I99I), os briquetes possuem no mínimo cinco vezes mais energia que os resíduos que os originaram, sendo que o seu poder calorífico é superior ao da lenha, tornando-os viáveis para confecção de alimentos.

A maioria dos resíduos de biomassa tem baixo teor de cinzas, exceto a casca de arroz que pode conter até cerca de $25 \%$ de cinzas, devido ao alto conteúdo de sílica da matéria-prima. Em muitas utilizações, o consumo de carvão é maior do que o dos briquetes. Dado o maior poder calorífico, utilizam-se menos briquetes do que lenha na queima (Boas et al., 2010).

De acordo com Dias et al. (2012), a qualidade dos briquetes e péletes está diretamente relacionada com as suas propriedades químicas, físicas e mecânicas. Essas propriedades determinam a qualidade do briquete ou palete no que se relaciona à resistência (na armazenagem, transporte e uso) ou na determinação de composição química, que por sua vez, pode gerar cinzas ou emissões gasosas indesejáveis durante a queima. 
o briquete possui um papel relevante, competindo diretamente com a lenha e o carvão vegetal, uma vez que a quantidade de carvão por exemplo, utilizada em alguns estabelecimentos comerciais poderia ser reduzida a mais que metade se introduzisse os briquetes no lugar deste (GENTIL, 2008).

D4: de acordo com Dias et al. (2012), os briquetes podem ser preparados em diferentes formatos (retangular, ovoide, cilíndrico, tetraédrico, travesseiro entre outros) e tamanhos, de acordo com o tipo de compactadora utilizada ou a forma como compactamos na mão. O mesmo se aplica para os péletes, especialmente na área alimentícia em que os formatos são bastante variados. A principal diferença entre os péletes e os briquetes, entretanto, está nas dimensões. Os péletes, normalmente, têm diâmetro entre 6 e $16 \mathrm{~mm}$ e comprimento de 25 a $30 \mathrm{~mm}$, enquanto os briquetes têm diâmetro entre 50 e $100 \mathrm{~mm}$ e comprimento entre 250 a $400 \mathrm{~mm}$. Porém esses valores podem variar, de acordo com a demanda do cliente, ou mesmo para atender especificações internacionais.

Briquetagem ou peletização são processos muito vantajosos no que diz respeito à armazenagem e transporte do material. Com a briquetagem ocorre uma grande redução de volume do material, o que implica em um armazenamento de energia maior em um menor espaço para estocagem. Além disso, há vantagem de diminuir os custos com o transporte, pois uma quantidade muito superior de biomassa poderá ser transportada em espaço físico reduzido. Se comparados com madeira, péletes e briquetes representam ganho de espaço e esse ganho é ainda maior se comparado com a matéria-prima de origem (finos de carvão, papel, serragem, casca, palha etc.), pois a redução de volume é, em média, de 4 a 6 vezes, podendo chegar até a II vezes em relação ao volume da biomassa de origem (Dias, et al., 2012; Boas et al., 2010; De Ramos et al., 20II).

\section{CONCLUSÕES}

Conforme os resultados, pode-se concluir que os briquetes produzidos com finos de carvão vegetal e papel residual se mostraram fonte alternativa viável para a geração de energia e o reaproveitamento desse material, reduzindo a pressão sobre a fonte de extração de madeira 
para produção de combustível. Da mesma forma que a metodologia utilizada para produção de briquetes fira como potencial na conservação ambiental por se utilizar meramente material residual.

Observou-se também que os briquetes produzidos reúnem condições para serem utilizados como combustível alternativo, tendo se revelado os finos de carvão vegetal e papel como matérias que agregam um poder calorifico.

Por sua vez, em compara com o carvão vegeta, por exemplo, os briquetes produzidos, mostramse eficazes, observável pelos testes realizados, onde nota-se sua boa combustão, sem muita fumaça, quantidade bem reduzida para confecção de alimentos, tempo de cozedura aceitável e com um tempo de combustão também, bom.

Constatou-se por último, que o tamanho dos briquetes pode variar conforme o modo de preparo, a forma como compactamos ou o molde que se for a usar, em casos onde a produção pode ser mecanizada, que não foi o caso em estudo, pois a compactação foi meramente manual, podendo também variar conforma a qualidade de material a compactar na palma da mão.

\section{REFERÊNCIAS}

BAIliS, R.; RUJANAVECH, C.; DWIVEDI, P.; VIlELA, A.O.; CHANG, H.; MIRANDA, R.C. Innovation in charcoal production: A comparative life-cycle assessment of two kiln technologies in Brazil. Energy for Sustainable Development, v.17, p.189-200, 2013

BORGES, Fabricio; SELLIN, Noeli; MEDEIROS, Sandra Helena Westrupp. Caracterização e avaliação de lodos de efluentes sanitário e industrial como biomassa na geração de energia. Ciência \& Engenharia, v. I7, n. I/2, p. 27-32, 2008.

DELATORRE, Fabíola Martins et al. Insights acerca do uso de finos de carvão vegetal para geração de bioenergia. 2020 .

DE OLIVEIRA SACCOL, Ângelo Fernando et al. Aproveitamento de biomassa florestal na fabricação de briquetes. In: ANAIS DO II CONGRESSO INTERNACIONAL DE BIOMASSA. p. 5I., 2020. 
Revista Ibero- Americana de Humanidades, Ciências e Educação- REASE $\quad{ }^{\text {open }}$ Access

DE RAMOS, Luana Elis et al. Produção e avaliação de briquetes de resíduos lignocelulósicos. Pesquisa Florestal Brasileira, v. 31, n. 66, p. 103-103, 2011.

DE SENA, R. F. Avaliação da biomassa obtida pela otimização da flotação de efluentes da indústria de carnes para geração de energia. Dissertação de Mestrado. EQA/UFSC, Florianópolis, fev. 2005.

DELATORRE, Fabíola Martins et al. Insights acerca do uso de finos de carvão vegetal para geração de bioenergia. 2020.

DIAS JÚNIOR, A. F.; ANDRADE, A. M.; COSTA JR., D. S. Caracterização de briquetes produzidos com resíduos agroflorestais. Pesquisa Florestal Brasileira, Colombo, v. 34, n. 79, p. 225-234, 2014 .

DIAS JÚNIOR, A. F., ANDRADE, C. R, PROTÁSIO, T. P., et al. "Pyrolysis and wood byproducts of species from the Brazilian semi-arid region”, Scientia Forestalis, v. 46, n. II7, pp.6575, 2018.

DIAS, JMC de S. et al. Produção de briquetes e péletes a partir de resíduos agrícolas, agroindustriais e florestais. Embrapa Agroenergia-Documentos (INFOTECA-E), 2012.

GENTIL, L. V. Tecnologia e economia do briquete de madeira. Tese (Doutorado em Engenharia Florestal) - Universidade de Brasília, Brasília, DF, 2008. 196 p.

IRA, A. T. O., NASCIMENTO, A. M., ANDRADE, A. M., et al."Propriedades termoquímicas de briquetes produzidos com finos de carvão vegetal e resíduos de Pinus spp", Scientia Forestalis, v. 46, n.II9, pp.483-493, 2018

JÚNIOR, Ananias Francisco Dias et al. Produção de briquetes de moinha de carvão vegetal e resíduos lignocelulósicos visando uso bioenergético Production briquettes from the fines of Charcoal and Lignocellulosic residues for bioenergetics use, 2016 
MACHADO, J.G.M.S.; OSÓRIO, E.; VILELA, A.C.F. Reactivity of brazilian coal, charcoal, imported coal and blends aiming to their injection into blast furnaces. Material Research, v.13, n.3, p.287-292, 2010 .

MAGALHÃES, Arthur Santos; SILVA, Tiago Miguel Martins; CASTRO, Vinicius Gomes. Produção e caracterização de briquetes a partir de resíduos sólidos e prensagem semimanual. Advances in Forestry Science, v. 6, n. 3, p. 705-710, 2019.

MARTINS, Mariana Provedel et al. Produção e avaliação de briquetes de finos de carvão vegetal compactados com resíduo celulósico proveniente da indústria de papel e celuloser. Revista Árvore, v. 40, n. I, p. 173-18o, 2016.

NUNES, Eduardo Z.; ANDRADE, Azarias M. de; DIAS JÚNIOR, Ananias F. Production of briquettes using coconut and eucalyptus wastes. Revista Brasileira de Engenharia Agrícola e Ambiental, v. 23, n. II, p. 883-888, 2019.

PROTÁSIO, Thiago de Paula et al. Correlações canônicas entre as características químicas e energéticas de resíduos lignocelulósicos. Cerne, v. I8, n. 3, p. 433-439, 2012.

QUIRINO, W. F.; VAlE, A. T.; ANDRADE, A. P. A.; ABREU, V. L. S.; AZEVEDO, A. C. S. Poder calorífico da madeira e de materiais lignocelulósicos. Revista da Madeira, Curitiba, n. 89, p. 100-106, 2005.

ROUSSET, P.; PIRES, A.C.; SABLOWSKI, A.; RODRIGUES, T. LCA of eucalyptus wood charcoal briquettes. Journal of Cleaner Production, v.19, p.1647-1653, 2011.

SILVA, Márcio Magalhães da. A formação de competências socioemocionais como estratégia para captura da subjetividade da classe trabalhadora. 2018.

SILVA, Victória Viana et al. Poder calorífico de briquetes artesanais fabricados com diferentes tipos de aglutinantes. In: Embrapa Florestas-Artigo em anais de congresso (ALICE). In: SEMINÁRIO DE INICIAÇÃO CIENTÍfICA, 7., 20I8, Sabará. [Anais]. Sabará: IFMG, 2018., 2018. 
VIEIRA, A. T. O.; NASCIMENTO, A. M.; ANDRADE, A. M.; DiAS JÚNiOR, A. F. Physical-mechanical properties of briquettes produced from charcoal fines and waste of Pinus spp. Floresta, v. 48, n. 4, p. 513-522, 2018.

Vilas BOAS, M. A., CARneiro, A. C.O., VitAl, B. R., CARVAlHO, A. M.M. L., MARTINS, M. A. Efeito da temperatura de carbonização e dos resíduos de macaúba na produção de carvão vegetal. Scientia Forestalis, Piracicaba, v. 38, n. 87, p. 481-49o, 2010.

VITAL, B.R., CARNEIRO, A.C.O., PEREIRA, B.L., “Qu id de d deir p r fins energéti os”, In: Santos, F., Colodette, J., Queiroz, J. H. (Org.), Bioenergia \& Biorrefinaria: Cana-de-Açúcar \& Espécies Florestais, I ed., pp. 321-354, Visconde do Rio Branco, Suprema, 2013.

FAO. FAOSTAT. Disponível em: Acesso em: 20 fev. 202rb. 